\title{
Mobile Convergence and Entrepreneurial Opportunities for Innovative Products and Services
}

\author{
Jeff Moretz and Chirag Surti
}

\author{
"Seriously, we are in the midst of the convergence of voice" \\ and data and that is challenging the infrastructure of \\ the telephone companies. There are huge commercial \\ interests in the basic technology, but even more so in \\ content delivery and control of content.
}

Steve Crocker

Visionary, inventor, and Internet Hall of Fame inductee

\begin{abstract}
Our research on 2012 and 2013 Canadian wireless service pricing indicates that data was underpriced relative to traditional voice and text messaging services. Such a situation, while potentially disadvantaging consumers of traditional mobile services, created a market that favoured competitors pursuing innovative uses of mobile data. Although more competitive pressures in the telecommunications market would provide broader benefits to Canadian consumers and facilitate greater innovation in related services, a favorable pricing differential vis-à-vis data transmission provides useful incentives. Even with recent changes to the pricing of mobile services in Canada, we should expect continued development of services that substitute data for voice and text messaging, particularly for international communications, as well as more innovative uses of mobile data.
\end{abstract}

\section{Introduction}

The rapid expansion and improvement of digital wireless networks has created a sea change in the expectations among consumers regarding connectivity. Smartphones are becoming ubiquitous, and they are among the most rapidly adopted consumer technologies in history. DeGusta (2012) reported that smartphones were on pace to saturate North American and World markets in record time, and most US phones, including the vast majority of new phone purchases, are smartphones (Reed, 2013). Services such as Twitter and Vine were tailored for the mobile market from the start, and major industry players from Google to Facebook to Twitter have scrambled to stake their claim in the mobile space.

Yet, despite the rapid growth of this market, there is sometimes the perception that only the very large global competitors are able to compete in this new domain.
However, the success of Apple's AppStore and the more recent Google Play means that developers of software and associated services that leverage mobile technologies have the opportunity to reach millions of potential customers with relatively limited marketing and distribution budgets. In fact, the digital landscape makes it more rather than less feasible for upstarts to disrupt more established players (Davis, 2014), at least in many competitive domains. The AppStore alone generated $\$ 10$ billion in sales in 2013 (Apple Press Info, 2014) across more than a million different apps (148Apps.biz, 2014). Google Play passed the 25 billion app download mark more than a year ago (Webster, 2013), and although revenues still lag behind the AppStore, the gap is narrowing (Perez, 2014).

All of this begs the question: what is the impact of Canada's uncompetitive telecommunications landscape on such entrepreneurship? It is well established that telecommunications services in Canada are not 


\section{Mobile Convergence and Entrepreneurial Opportunities}

\section{Jeff Moretz and Chirag Surti}

competitive, and that Canadian consumers pay more for less (Christopher, 2013), in large part due to the lack of effective competition (Surti \& Moretz, 2013). However, there are some reasons for hope when it comes to telecommunications related entrepreneurship.

In order to detail the situation that pertains in the Canadian telecommunications market and the opportunities that this market presents for innovation, we first discuss the Canadian wireless market and examine the advertised pricing data of the three major service providers to infer the marginal cost of the various services. We then examine the pricing inefficiencies that arose under the pricing plans available to Canadian consumers in 2013 and the implications of these plans regarding incentives and substitution effects. We close with discussion of innovation opportunities provided by this market situation and by the infrastructure that has developed around smartphones and other mobile devices in particular.

\section{The Canadian Wireless Market}

Based on our analysis of the pricing of Canadian telecommunications services from 2012 to 2013, mobile data has been effectively cross-subsidized by the fees for voice calls and text messaging (i.e., short messaging service [SMS]). Thus, software and services that utilize the data stream of a mobile device were making use of a cheaper service option, giving such services an advantage in the marketplace and providing a stimulus for innovation and entrepreneurship in the Canadian mobile communications space.

Though such innovations have provided some relief for consumers, the Canadian telecommunications market remains uncompetitive, in part because of the high cost of entry for carriers. Telecom carries must invest enormous amounts of capital upfront in the acquisition of spectrum and development and maintenance of networks in order to provide sufficiently broad coverage. The cost of adding one more individual to the service is negligible in comparison to the costs of creating a viable network, and any calculation of the cost of providing services would need to amortize these fixed costs for many years across all of the customers served. However, even if we were to undertake such a calculation of service costs, we do not have access to the requisite detailed cost data. The telecommunications providers do not publish such data for strategic and competitive reasons. Thus, we must approach the problem from a different angle.
Although the data on the actual costs borne by the providers themselves is not readily available, we do have extensive access to consumer pricing information. Because the telecommunications providers operate an extensive retail operation, selling services directly to both individual consumers and small businesses, they make pricing information widely available as part of their marketing efforts. Using multiple linear regression (tinyurl.com/yqxx8v), we analyse 2012 and 2013 advertised pricing information across all retail plans offered by each of the "Big 3" Canadian telecommunications companies and their subsidiaries: Rogers (rogers.com), TELUS (telus.com), and Bell (bell.ca). The advertised price data were collected during the summer of 2012 and 2013 from their respective websites. We deliberately ignored short-term "teaser rates" and promotional pricing and instead focused on the published retail pricing that most consumers end up paying in the long run.

The use of multiple linear regression to estimate implied cost is a well-established approach in economics. For businesses that have very high fixed cost and negligible marginal cost of operation, it is possible to infer the cost component of each offering using advertised rates. In economics, this is referred to as the shadow price (tinyurl.com/24k7be). Given that the underlying telecommunications infrastructures used by the different providers are quite similar within each technological generation and all providers operate well above minimum efficient scale, such costs can be discounted as a source of cost differences between service providers. Therefore, by advertising information about their offerings and announcing the prices charged for variety of bundled options, the telecommunications companies reveal useful information about their cost structure for providing each of the three services to the consumer. The cost estimates of the service components for each of the three service providers are presented in Table 1. Here, we highlight the estimated cost of voice, text, and data implied by published pricing data along with advertised overage charges. This method allows us to estimate the implied marginal costs of one minute of voice, one text message, and one GB of data with statistical confidence (the $\boldsymbol{p}$ values and the $\boldsymbol{F}$ statistics were all significant at $95 \%$ level of significance). Although these values are indirect estimates of costs, we confirm them with reference to the data equivalent of voice transmissions.

In Table 1, we resolve the bundled telecom plan into its main cost components. Our analysis shows that there is a significant fixed cost component for simply connecting a customer to the network, as implied by the base 


\section{Mobile Convergence and Entrepreneurial Opportunities}

\section{Jeff Moretz and Chirag Surti}

Table 1. Canadian mobile telecommunications main cost components (based on 2013 data)

\begin{tabular}{cccccccc}
\hline & & \multicolumn{2}{c}{ Voice } & \multicolumn{2}{c}{ Text } & \multicolumn{2}{c}{ Data } \\
\cline { 3 - 7 } Provider & $\begin{array}{c}\text { Base } \\
\text { Connection Fee }\end{array}$ & Per minute & Overage & $\begin{array}{c}\text { Per } \\
\text { message }\end{array}$ & Overage & Per GB & Overage \\
\hline Rogers & $\$ 50.52$ & $<\$ 0.01$ & $\$ 0.45$ & $\$ 0.00$ & $\$ 0.20$ & $\$ 10.91$ & $\$ 21.25$ \\
\hline TELUS & $\$ 58.95$ & $<\$ 0.01$ & $\$ 0.43$ & $\$ 0.00$ & $\$ 0.20$ & $\$ 9.19$ & $\$ 20.00$ \\
\hline Bell & $\$ 44.86$ & $<\$ 0.01$ & $\$ 0.50$ & $\$ 0.00$ & $\$ 0.20$ & $\$ 10.85$ & $\$ 22.00$ \\
\hline
\end{tabular}

connection fee, or a monthly fee in industry parlance. Such a connection cost is to be expected in an industry with such an enormous fixed cost component. As the table shows, there are some substantial differences between the carriers in terms of the implied costs of building and maintaining the basic network infrastructure. These differences are perhaps due to historical accident, operational scale, technological sophistication, and market demographics, but they are not the focus of our discussion here. Without technological developments that radically reduce the costs associated with developing an extensive network of towers and switching equipment, this element of the pricing of service provision is unlikely to decline dramatically as a proportion of the overall cost structure, and it does little to elucidate the opportunity for mobile services innovation that we hope to see in the Canadian market.

\section{Market Constraints, Inefficiencies, and Innovation}

Because the marginal cost of voice calls and text messaging is negligible, once the consumer is connected to the network, the cost of providing additional voice and text services is negligible. The fact that voice minutes were limited by providers indicates a significant markup given the negligible cost of provision. In addition, consumers were heavily penalized for exceeding their allocated quota of voice and text; in our analysis, the overage charge mark-up on voice was approximately $4500 \%$ and for text it was almost $20,000 \%$. For data however, in terms of overage charges, the mark-up on average was only $105 \%$, substantially lower when compared to voice and text overage charge mark-ups. The fact that published prices imply limited cost for providing voice and text services coupled with the strong influence of data on plan prices indicates that the cost structure is dominated by data volume. This finding from our analysis, coupled with the prevalence of limited voice minutes and text messages and the dramatic difference between the overage mark-up for voice and text relative to data, indicates an effective subsidy on data usage in the form of disproportionate mark-ups on voice and text services. Thus, consumers of voice and text are in effect cross-subsidizing heavy consumers of data. This subsidization might be especially true for lower-tier service plans or voice-only plans for which consumers pay significantly more than the implied cost to provide voice services, as well as for consumers who feel compelled to purchase plans with features and data allowances that they do not need in order to get the voice minutes they want.

Such cross-subsidization of data has significant implications for the development of software and services that utilize mobile data transmissions. Under such pricing schemes, mobile phone users who primarily make use of voice or text messaging are disadvantaged, while those consumers who use data services pay comparatively less for that aspect of service relative to the cost of provision. It is relatively easy and quite instructive to highlight the overpricing of voice minutes in the Canadian market. Assuming that the encoding used for proprietary mobile networks is similar to the G.711 standard (tinyurl.com/yoz6q5) used in telephony DS0 channels (tinyurl.com $/ \mathrm{kwaol} / \mathrm{v}$ ), the conversion of voice to data would be: $64 \mathrm{kbps} \times 9.5367 \times 10^{-7} \mathrm{gb} / \mathrm{kb} \times 60$ seconds $=$ $.003662 \mathrm{gbpm}$ or 273 minutes per gigabit. Whereas a voice minute transmitted as overage would cost 46 cents, that same voice transmission using data overage would cost less than 8 cents/minute, making it substantially cheaper than voice overage. In fact, most wireless carriers used codecs similar to those used for Voice over Internet Protocol (VoIP), achieving low latency, 


\section{Mobile Convergence and Entrepreneurial Opportunities}

\section{Jeff Moretz and Chirag Surti}

high-quality transmission at data rates less than $10 \%$ those required by G.711 transmission. At $6.3 \mathrm{kbps}$, the higher data rate possible using G.723.1 (tinyurl.com/ 33hy5s), the data equivalent of one minute of voice would cost less than $\$ 0.01$, which is precisely what our analysis shows. Overpricing of voice and text transmission by service providers, both globally and in Canada, has spurred the creation of a variety of innovative solutions by third-party developers to transmit voice and text messages using data.

Thus, entrepreneurs who developed software and services that leverage data transmission should experience a comparative advantage by virtue of the effective subsidy on data rates. The advantages to innovation of what amounts to a subsidy on mobile data proposed here are compatible with arguments regarding mobile web development proposed in Ville Saarikoski's (2006) $\mathrm{PhD}$ dissertation at the University of Oulu in Finland, in which he characterizes email specifically, and the mobile Internet more broadly, as disruptive technologies (cf. Bower \& Christensen, 1995).

Saarikoski's dissertation argues that SMS or text messaging is far less efficient than email at creating scalefree networks. In essence, email connectivity (and communications via other technologies that use similar network connectivity approaches) requires fewer steps on average to connect any given node to another node. Saarikoski extends the insights related to scale-free networks to argue that value-added services (e.g., beyond traditional voice calling) could be increased in a mobile packet-based (digital) network. For example, NTT DoCoMo's i-mode service (tinyurl.com/nlkqtq) in Japan had achieved significant market success by adopting a packet switched network that facilitated non-voice communication and enabled extensive development of third-party services from which i-mode earned a revenue-sharing percentage (Mallon, 2013). However, carriers in Europe failed to adopt similar structures, which may have played a significant role in the slow growth of mobile data networks and associated services in the European market.

More importantly for our present argument, Saarikoski's dissertation also argues that the pricing associated with the European networks inhibited adoption in multiple ways, including connection costs and usage fees. DoCoMo's success was in part attributable to its decision to focus on the consumer market, where buyers were less conservative and more willing to experiment with new technologies than were many busi- ness customers. Apple followed a similar path to market success with its line of i-products, with consumer adoption preceding eventual expansion into the business market. However, the success of $\mathrm{i}$-mode is also intimately connected to its decision to leverage packet data and offer reasonable pay-per-use pricing to facilitate innovation in third-party services (Grech, 2003).

\section{Opportunities for Innovation}

Innovation is directly related to the application of ideas or methods in ways that provide greater value to society (McIntyre, 1982). Value, for both consumers and businesses, includes cost factors as well as benefits provided (Anderson \& Narus, 1998; Ratchford, 1982). In the context of mobile telecommunications, applications that provide opportunities to substitute comparatively underpriced data for overpriced voice and texting services provide cost-focused value to consumers. However, the same innovations that provide those costsaving opportunities also provide richer, more effectively integrated communications services that increase customer benefits.

Among the more famous of the app-based communications solutions are WhatsApp (whatsapp.com) and Viber (viber.com). Facebook recently acquired WhatsApp for $\$ 19$ billion in cash and stock and Viber was purchased by Rakuten, a Japanese e-commerce company, for almost $\$ 1$ billion. These transactions are testaments to the value of each solution's user bases, which number in the hundreds of millions. In addition to these more recent players, some of the early VoIP pioneers such as magicJack and Vonage have launched mobile apps that extend their service from simple landline telephony replacement into a mobile platform offering seamless voice communications. Such services can be very attractive to consumers because of the effective subsidization of data transmission by wireless service providers. These services also present opportunities for greater value creation through the integration of multiple forms of communication in a fashion that is not compatible with the traditional paradigm that voice communication is different than and separate from data.

Businesses may also substitute text data for voice communications when contacting customers. Businesses such as financial service providers, cable providers, water/power/gas utilities, and telecommunication service providers themselves can communicate upcoming bill payments, changes to account details, or upcoming planned outages of services via multiple channels in- 


\section{Mobile Convergence and Entrepreneurial Opportunities}

\section{Jeff Moretz and Chirag Surti}

cluding text messages. Such simple innovations with such significant potential to decrease costs, increase service quality, and dramatically improve overall profitability have remained virtually absent from Canadian marketplace, in part because of the consumer costs associated with their adoption. In India, where text messages are usually free and unlimited, most businesses, including financial services and utilities, make extensive use of SMS to communicate with customers. One substantial driver of the slower rate of adoption of such service innovations in Canada may be privacy and security concerns on the part of Canadian companies and the Canadian government, rendering such innovations infeasible. Yet, the fact remains that, from a cost-ofbusiness point of view, such mechanisms represent significant efficiency improvement opportunities while also providing opportunities for enhanced customer service. Similarly, the success of online messaging services such as Skype, WhatsApp, and Viber bears testament to the fact that consumers have been very interested in alternatives to comparatively overpriced voice calling, text messaging (SMS), and multimedia messaging services (MMS).

\section{Conclusion and Insights: Innovation Opportunities}

The apps noted above represent but a small proportion of the explosion of apps that has arisen. The industry's shift from mobile phones with expanded capabilities to more flexibly functional mobile computing devices has changed the innovation landscape. The history of Research in Motion (RIM)/BlackBerry (blackberry.com) is informative. The Blackberry devices and their secured push-messaging service had enormous success because of their innovative solution to mobile communications problems, specifically reliable and secure transmission of email, avoiding the problems and excessive costs associated with mobile messaging (Gustin, 2013). Yet, RIM failed to expand its target market and neglected the benefits of broader innovation by third-party participants, particularly in the large consumer segment of the mobile market. As research has pointed out, Apple similarly neglected third-party developers at the initial launch of the iPhone but quickly moved to facilitate outside development when the market moved in that direction (West \& Mace, 2010).

Although competition in the market for apps is fierce, particularly on Apple's closely managed AppStore (Lagorio-Chafkin, 2010), there are opportunities for smaller competitors to enter the industry. As of March
2014, there were more than 300,000 publishers of apps for Apple's products in the U.S. (148Apps.biz, 2014). In many respects, the AppStore and Google Play can be seen as a mechanism for lowering the obstacles to innovation by providing a platform that reduces the need for extensive investment in distribution and support capabilities. More broadly, the rise of the smartphone and similar mobile devices presents opportunities for substantial innovation in much more focused domains. Even where a robust market willing to purchase a tailored application is absent, businesses often find it desirable to create custom applications (cf. Apple Developer, 2014). This expansion of opportunities for customer-driven innovation is akin to the "user toolkits" concept promulgated by von Hippel (2001, von Hippel \& Katz, 2002) among others. In the case of mobile telecommunications, the "smart" devices themselves may serve as the foundation for user-driven innovation with some additional support available through the distribution and support infrastructures of the device champions (e.g., Apple and Google).

Mobile commerce has also seen significant increase in interest as expanding mobile device capabilities make myriad approaches feasible (Ho \& Kwok, 2003). Going forward, the growing success of phone- and text-based payment services such as mpessa in Asia and Africa, as well as increased use of virtual wallets using near field communication (NFC) technology and the rise of the "crypto currencies" may hasten the creation of more innovation in the West, which relies more extensively on data rather than voice and text.

Although the differences in pricing and the implied costs of service provision between various types of mobile telecommunications has historically presented some relative advantages for developers of digital products and services that utilize mobile data, we should note that the lack of competitiveness in the telecommunications sector still represents a significant obstacle to Canadian competitiveness in general and to innovation in the mobile space in particular. The structure of offerings in the consumer market may tend to offset such negative effects in certain domains by presenting consumers with data service at a price that is effectively subsidized by text and voice mark-ups, but innovation will still experience negative effects from the lack of a competitive market for mobile telecommunications.

Although there were potential advantages for innovators using mobile data under the pricing structures in 


\section{Mobile Convergence and Entrepreneurial Opportunities}

\section{Jeff Moretz and Chirag Surti}

place in 2012 and 2013, all innovative activities would benefit from lower prices and the spark to innovation in basic telecommunications provision that effective competition would provide. The recent simplification of mobile pricing plans (CBC News, 2014) is a small step toward a more consumer-friendly market, and to the extent that such changes encourage more extensive and intensive adoption of mobile data services, they will help foster innovation among third-party app developers and service providers. However, the fact that all plans are identical and involve substantial price increases shows that competition is lacking, with the threat of regulatory changes sparking the move to simpler pricing structures. Our analysis of the new plans reveal that in effect the data is priced at $\$ 6.21$ per GB and the monthly access fee or the base fee is $\$ 60.95$ and a phone subsidy of $\$ 20.00$ is offered to consumers.

In fact, the revised plans, if anything, actually reduce the impetus to develop innovative products and services that utilize mobile data. If the mobile Internet is to live up to its potential as a disruptive technology, changing the nature of our interactions, we must foster the same kind of open innovation that has led to such incredible developments in the wired web. Although innovation is proceeding in mobile services, a more competitive market for basic mobile telecommunications service would greatly enhance opportunities for innovation that none of us can readily envision.

Thus, despite the lack of competitiveness of the Canadian telecommunications sector, a situation that deters innovation and the spread of potentially valuable services and capabilities, the structure of offerings may have served to counteract those negative effects for some products and services. There are many sectors of the Canadian economy that stand to benefit from more competitive pricing in mobile services in general and mobile data in particular. Mobile financial services are one area that has seen tremendous development globally, and the Canadian market now has its first open mobile wallet solution (CNW, 2013) using mobile phone data capabilities to manage payments and loy- alty program points from President's Choice Financial and TD Bank Group. Mobile gaming, particularly games that require extensive data communications in order to facilitate real-time interactive gameplay, could also benefit from pricing rationalization. For example, Ingress (ingress.com) utilizes mobile data connectivity, GPS, etc. in order to create an integrated augmentedreality gaming environment. Games such as Shadow Cities (no longer available) and Parallel Kingdom (parallel kingdom.com) take a similar approach, and there are myriad other ways to enhance mobile gaming through data connectivity. Canada has a significant presence in the gaming domain, with major companies operating in Montreal, Toronto, Vancouver, and elsewhere across the country, and mobile gaming of all sorts could see more extensive adoption and development if given the opportunity to leverage cheap and reliable data connectivity.

More broadly, we should expect to see innovations in areas that are not receiving significant attention at present. The wonderful thing about market structures that foster innovation is that we all benefit from developments that few of us could predict and that many of us would discount, but that the energetic, creative, ambitious, and determined entrepreneurs among us are willing to bet on with everything they have. The best we can do for them is to provide an equable playing field.

\section{Recommended Reading}

- Global Technology, Media, Telecom Innovation Series (PricewaterhouseCoopers, 2014; tinyurl.com/pscsp2q)

- "Disruptive Technologies" (Manyika et al., 2013; tinyurl.com/nmbecug)

\section{Acknowledgements}

The authors wish to thank recent UOIT graduates, Darryl Hand and Kaileigh Peace, for collecting the data used in this study. 


\section{Mobile Convergence and Entrepreneurial Opportunities}

\section{Jeff Moretz and Chirag Surti}

\section{About the Authors}

Jeff Moretz is Assistant Professor of Strategy and Entrepreneurship at the University of Ontario Institute of Technology (UOIT) in Oshawa, Canada. He obtained his PhD from the University of Texas at Austin, USA, and has an MBA and two undergraduate degrees from Michigan State University, USA. He is a recovering consultant, having worked for McKinsey \& Company in Chicago after his MBA studies. Prior to joining the UOIT, he worked at University College Cork in Ireland, researching open source software communities and open innovation. His research interests focus on the impact of information, openness, and information technologies on innovation, business models, and strategies.

Chirag Surti is an Assistant Professor of Logistics and Supply Chain Management at the University of Ontario Institute of Technology (UOIT) in Oshawa, Canada. He earned a $\mathrm{PhD}$ degree from McMaster University in Hamilton, Canada, and a Master of Science in Industrial Engineering from the State University of New York in Buffalo, USA. His primary research interest is in the area supply chain management and understanding and analyzing the role process innovation can play in boosting productivity. $\mathrm{He}$ is a recipient of NSERC Discovery and SSHRC Partnership grants.

\section{References}

148Apps.biz. 2014. Apple iTunes App Store Metrics, Statistics and Numbers for iPhone Apps. 148Apps.biz. June 1, 2014: http://148apps.biz/app-store-metrics/

Anderson, J. C., \& Narus, J. A. 1998. Business Marketing: Understand What Customers Value. Harvard Business Review, 76(6): 53-67.

Apple Developer. 2014. Develop Custom iOS Apps for Business. Apple Developer. June 1, 2014:

https://developer.apple.com/programs/volume/b2b/

Apple Press Info. 2014. App Store Sales Top \$10 Billion in 2013. Apple Press Info. June 1, 2014:

http://www.apple.com/pr/library/2014/01/07App-Store-SalesTop-10-Billion-in-2013.html

Bower, J. L., \& Christensen, C. M. 1995. Disruptive Technologies: Catching the Wave. Harvard Business Review, 73(1): 43-53.

CBC News. 2014. Wireless Carriers Hike Prices Across Canada. CBC News. June 1, 2014:

http://www.cbc.ca/1.2575886
Christopher, D. 2013, July 16. Confirmed: Canadians Pay Some of the Highest Prices for Some of the Worst Telecom Service in the Industrialized World. OpenMedia.ca. June 1, 2014:

https://openmedia.ca/blog/confirmed-canadians-pay-somehighest-prices-some-worst-telecom-service-industrialized-world

CNW. 2013. PC Financial and TD Announce Ugo - Canada's First Open Mobile Wallet. NewsWire.ca. June 1, 2014:

http://cnw.ca/Mb9Ql

Davis, J. P. 2014. How To Create A "Killer App": A Guide For Entrepreneurs. Forbes. June 1, 2014: http://www.forbes.com/sites/insead/2014/03/18/how-to-create-akiller-app-a-guide-for-entrepreneurs/

DeGusta, M. 2012, Are Smart Phones Spreading Faster than Any Technology in Human History? MIT Technology Review (May). June 1, 2014:

http://www.technologyreview.com/news/427787/are-smart-

phones-spreading-faster-than-any-technology-in-human-history/

Grech, S. 2003. Case: i-Mode Pricing. Seminar on Internet Pricing and Charging, S-38.042. Helsinki: TKK Networking laboratory, Helsinki University of Technology.

http://www.netlab.hut.fi/opetus/s38042/k03/topics/imodepricing.pdf

Gustin, S. 2013. The Fatal Mistake That Doomed BlackBerry. Time (July). June 1, 2014:

http://business.time.com/2013/09/24/the-fatal-mistake-thatdoomed-blackberry/

Ho, S. Y., \& Kwok, S. H. 2002. The Attraction of Personalized Service for Users in Mobile Commerce: An Empirical Study. ACM SIGecom Exchanges, 3(4): 10-18.

http://dx.doi.org/10.1145/844351.844354

Lagorio-Chafkin, C. 2010. How to Make Money on iPhone Apps. Inc.com. June 1, 2014:

http://www.inc.com/guides/making-money-iphone-apps.html

Mallon, D. 2013. Where Are They Now? i-mode. ZDNet. June 1, 2014: http://www.zdnet.com/uk/where-are-they-now-i-mode7000021216/

Manyika, J., Chui, M., Bughin, J., Dobbs, R., Bisson, P., \& Marrs, A. 2013. Disruptive Technologies: Advances That Will Transform Life, Business, and the Global Economy. New York, NY: McKinsey Global Institute.

McIntyre, S. H. 1982. Obstacles to Corporate Innovation. Business Horizons, 25(1): 23-28. http://dx.doi.org/10.1016/0007-6813(82)90040-4

Perez, S. 2014. Google Play Still Tops iOS App Store Downloads, And Now Narrowing Revenue Gap, Too. TechCrunch. June 1, 2014: http://techcrunch.com/2014/04/15/google-play-still-tops-ios-appstore-downloads-and-now-narrowing-revenue-gap-too/

PricewaterhouseCoopers. 2014. Global Technology, Media, Telecom Innovation Series. $P w C$. June 1, 2014: http://www.pwc.com/tmtinnovators

Ratchford, B. T. 1982. Cost-Benefit Models for Explaining Consumer Choice and Information Seeking Behavior. Management Science, 28(2): 197-212.

http://dx.doi.org/10.1287/mnsc.28.2.197

Reed, B. 2013. Smartphones Now Account for Almost Two-Thirds of All Mobile Phones in the U.S. BGR. June 1, 2014:

http://bgr.com/2013/09/18/smartphone-adoption-united-states/ 


\section{Mobile Convergence and Entrepreneurial Opportunities}

\section{Jeff Moretz and Chirag Surti}

Saarikoski, V. 2006. The Odyssey of the Mobile Internet - The Emergence of a Networking Attribute. PhD Thesis. Oulu, Finland: University of Oulu.

Surti, C., \& Moretz, J. 2013. Wireless is a necessity, so open the market. Financial Post. June 1, 2014:

http://opinion.financialpost.com/2013/07/05/verizon-canadawireless/

Von Hippel, E. 2001. User Toolkits for Innovation. Journal of Product Innovation Management, 18(4): 247-257.

http://dx.doi.org/10.1111/1540-5885.1840247
Von Hippel, E., \& Katz, R. 2002. Shifting Innovation to Users via Toolkits. Management Science, 48(7): 821-833.

http://dx.doi.org/10.1287/mnsc.48.7.821.2817

Webster, S. 2014. Google Play Blows Past 25 Billion App Downloads. AndroidGuys. June 1, 2014: http://www.androidguys.com/2012/09/26/google-play-blowspast-25-billion-app-downloads/

West, J., \& Mace, M. 2010. Browsing as the Killer App: Explaining the Rapid Success of Apple's iPhone. Telecommunications Policy, 34(5-6): 270-286.

http://dx.doi.org/10.1016/j.telpol.2009.12.002

Citation: Moretz, J., \& Surti, C. 2014. Mobile Convergence and Entrepreneurial Opportunities for Innovative Products and Services.

Technology Innovation Management Review, 4(6): 14-21. http://timreview.ca/article/800

Keywords: mobile convergence, innovation, entrepreneurship, wireless pricing, mobile services, competition, Canada 